\section{Questión}

Periodismo / Comunicación ISSN 1669-6581
- Av. $44 \mathrm{~N}^{\circ} 676,1^{\circ}$ piso

CP 1900 - La Plata - Argentina

www.perio.unlp.edu.ar/question

Pandemia por COVID-19: Un punto de partida para pensar las intersecciones entre especismo, medioambiente y alimentación

María Marta Andreatta - Alexandra Navarro - Silvina Pezzetta

https://doi.org/10.24215/16696581e355

\title{
Pandemia por COVID-19: Un punto de partida para pensar las intersecciones entre especismo, medioambiente y alimentación
}

\author{
COVID-19 pandemic: A starting point to think about the \\ intersections between speciesism, the environment and food
}

María Marta Andreatta

Centro de Investigaciones y Estudios sobre Cultura y Sociedad; Consejo Nacional de Investigaciones Científicas y

Técnicas/ Universidad Nacional de Córdoba

Licenciada en Nutrición (2002) y Doctora en Ciencias de la Salud (2010) UNC. Investigadora Adjunta CONICET, dedicada al estudio de los veg(etari)anismos en el marco de los Estudios Críticos Animales. Directora y docente del curso de postgrado "Alimentación veg(etari)ana: salud, ética y sustentabilidad" de la Escuela de Nutrición de la UNC. Es integrante del ILECA (Instituto Latinoamericano de Estudios Críticos Animales) y miembro del comité editorial de la Revista Latinoamericana de Estudios Críticos Animales. https://orcid.org/0000-0002-4715-6147 maryandreat@gmail.com

Alexandra Navarro

Instituto de Estudios Comunicacionales en Medios, Cultura y Poder Aníbal Ford; Facultad de Periodismo y Comunicación Social; Universidad Nacional de La Plata/ Instituto Latinoamericano de Estudios Críticos Animales Licenciada (2006), Profesora (2005) en Comunicación Social y Doctora en Comunicación (2016) Facultad de Periodismo y Comunicación Social de la Universidad Nacional de La Plata. Tesis doctoral "Representaciones e identidades del discurso especista: el caso de la carne vacuna y sus derivados en la Argentina (2000-2012)". Representante en Latinoamérica del ICAS (Institute for Critical Animal Studies) como directora del ILECA. Codirige la

Revista Latinoamericana de Estudios Críticos Animales (http://www.revistaleca.org). Coordina la UPID (Unidad de Promoción a la Investigación y el Desarrollo) "Estudios Críticos Animales y transdisciplinariedad". Profesora Adjunta Ordinaria de la Cátedra I Prácticas de la Enseñanza, Profesorado en Comunicación Social, FPyCS, UNLP. Fue becaria de CONICET de 2008 a 2017.

https://orcid.org/0000-0002-3429-249X aleximca@gmail.com 


\section{Resumen}

Dentro de estos impactos desconocidos, el lugar que ocupó la cría industrial de animales no humanos en la emergencia y la transmisión del COVID-19 es algo que permanece en la total ignorancia para la mayoría de la gente, que sigue asignando culpas a murciélagos o ciudades distantes con culturas diferentes. El incremento observado a nivel global de este tipo de enfermedades se relaciona tanto con la alteración de los entornos naturales como con el hacinamiento que resulta de la cría masiva de ganado para consumo humano. Según estimaciones recientes, alrededor del $60 \%$ de todas las enfermedades infecciosas en los seres humanos son de origen zoonótico. Si bien muchas de ellas se encuentran alojadas en la fauna silvestre, el ganado suele servir de "puente epidemiológico" hacia las poblaciones humanas.

\section{Palabras Claves}

especismo - medioambiente - alimentación

\section{Summary}

Within these unknown impacts, the place of industrial breeding of non-human animals in the emergence and transmission of COVID-19 is something that remains in total ignorance for most people, who continue to assign blame to bats or distant cities with different cultures. The overall increase in this type of disease is related to both the alteration of natural environments and the overcrowding resulting from the mass breeding of livestock for human consumption. According to recent estimates, about $60 \%$ of all infectious diseases in humans are zoonotic. While many of them are housed in wildlife, livestock often serve as an "epidemiological bridge" to human populations. 


\section{Key Words}

speciesism - environment - food

Desde hace ya varios años, las autoras de este escrito venimos trabajando, entre otras, la temática de la alimentación sin animales, buscando integrar en nuestras líneas de trabajo las complejas relaciones entre ética, política, dieta, salud y ambiente en el marco de los denominados estudios críticos animales, campo dedicado a la abolición de la explotación animal y ecológica, la opresión y la dominación, cuya meta es la supresión de la subordinación en diferentes ámbitos.

Pensar el mundo desde esta perspectiva supone, en primer lugar, asumir una postura política antiespecista --fundamentada en aportes provenientes de la ética, la filosofía moral, el derecho y la etología, principalmente-- que cuestione la discriminación o trato desventajoso e injustificado hacia aquellos individuos sintientes por no pertenecer a la especie humana. El especismo antropocéntrico - es decir, el que privilegia a la especie Homo sapiens - por analogía a los conceptos de sexismo, racismo, clasismo u homo-lesbo-transfobia, busca explicar el orden de dominación que se ejerce sobre aquellos seres vivientes que se agrupan bajo el término "animal". En tal sentido, puede ser entendido como un dispositivo de poder que ubica al ser humano como medida superior, mientras (re)produce la inferiorización sistemática de los vivientes no humanos. Esto implica, en la práctica, que el trato, los bienes, la ayuda y/o los derechos se atribuyan de manera perjudicial respecto de los individuos que no forman parte de la especie humana. Pero, además del especismo antropocéntrico, también puede suceder que se prefiera una especie de animal no humano por sobre otras. Esto habilita, por ejemplo, la protección de algunos (perros, gatos) y la explotación de otros (vacas, cerdos, pollos, peces para comida; ratones, monos u otros para experimentación, y un amplio etcétera). En suma, será un prejuicio antropocentrista, aunque no necesariamente consciente, el que guíe la toma de decisiones respecto de los demás animales, partiendo de la base de la superioridad de los seres humanos $y / 0$ de los animales que más se les parezcan o que cumplan funciones de compañía. Es este prejuicio a nivel individual y su dimensión estructural la que la política antiespecista busca revertir.

En el ámbito de lo alimentario, una postura antiespecista supone prescindir de todos los productos derivados, total o parcialmente, de animales no humanos, práctica referida comúnmente como "dieta vegana". En tal sentido, cabe mencionar que los discursos habituales 
sobre la alimentación de las personas suelen oscilar entre "veganas", "vegetarianas", "omnívoras" y "carnívoras", (mal)entendiéndose a estas dos últimas como desligadas de la voluntad y de la posibilidad de elección. Es importante explicitar que éstas son categorías de base biológica; así, los carnívoros son aquellos animales que necesitan obligadamente comer carne para sobrevivir y los omnívoros, animales - humanos o no humanos- que tienen la capacidad fisiológica de digerir tanto vegetales como carnes. Por esta confusión de términos, muchas veces se considera que las personas veganas o vegetarianas toman una decisión alimentaria ética, de manera consciente, mientras que los demás "sólo comen carne". En este marco, resulta de utilidad retomar el concepto de carnismo, acuñado por la estadounidense Melanie Joy, para hacer explícito que alimentarse de carne no está por fuera de los sistemas de creencias y valores de una persona. El mismo está fuertemente afianzado en la sociedad y resulta complejo abordarlo porque se encuentra normalizado, legitimado e invisibilizado.

El carnismo proporciona el soporte a un sistema alimentario que ha señalado a la carne como alimento fundamental, sinónimo simbólico de nutrición y de riqueza. El sostenimiento de tal sistema requiere de ciertas estrategias que no permitan a los sujetos conectar "carne" con "animales", y "animales" con "sintiencia"; es decir, pensar en ellos desde un lugar de empatía. Asimismo, necesita de todo un conjunto de prácticas productivas, como lo son la ganadería y la industria cárnica, así como de los consumos alimentarios de millones de personas que desconocen los procesos y los impactos de éstos en diversas aristas de su vida. Dentro de estos impactos desconocidos, el lugar que ocupó la cría industrial de animales no humanos en la emergencia y la transmisión del COVID-19 es algo que permanece en la total ignorancia para la mayoría de la gente, que sigue asignando culpas a murciélagos o ciudades distantes con culturas diferentes $-y$ que, por ello, resultan más sencillas de señalar-. Sin embargo, aunque no se descarta que la cría y consumo de animales silvestres haya sido el primer eslabón de la actual pandemia global, la cría industrial de animales también ha jugado un rol crucial. Esto no suele mencionarse debido, muy probablemente, no sólo a los intereses económicos involucrados, sino también a un necesario cambio de hábitos al que debería someterse la población, que involucra políticas públicas e importantes inversiones económicas en salud y educación.

Ante la actual pandemia de COVID-19, que nos ha enfrentado a una crisis sanitaria mundial sin precedentes, al menos en la historia reciente, se está poniendo un enorme énfasis en las medidas de prevención de contagio en las comunidades humanas y en desarrollar una vacuna 
que evite contraer la enfermedad, pero nada se discute acerca del sistema de explotación de vidas tanto humanas como no humanas y de los ecosistemas, que es un verdadero caldo de cultivo para la generación de enfermedades zoonóticas, tal como ocurrió con el Ébola, la gripe aviar o el SARS. El incremento observado a nivel global de este tipo de enfermedades se relaciona tanto con la alteración de los entornos naturales como con el hacinamiento que resulta de la cría masiva de ganado para consumo humano. Según estimaciones recientes, alrededor del $60 \%$ de todas las enfermedades infecciosas en los seres humanos son de origen zoonótico. Si bien muchas de ellas se encuentran alojadas en la fauna silvestre, el ganado suele servir de "puente epidemiológico" hacia las poblaciones humanas. Esto se encuentra potenciado en los sistemas de cría intensiva, con animales modificados genéticamente que carecen de la diversidad que le proporcionaría resistencia frente al contagio y que padecen una constante medicalización de su existencia para crecer más rápido, para evitar contraer enfermedades relacionadas con las condiciones en que son mantenidos y para no pudrirse, literalmente, en vida, al estar todo el tiempo sobre sus heces y lastimándose. Debido al continuo suministro de antibióticos y antivirales, y al estar inmunodeprimidos, resultan más propensos a contraer virus que luego pueden propagarse hacia escenarios lejanos de donde fueron criados, tal como sucede ahora con la pandemia que afecta al mundo. La industria alimentaria, que significa a los animales que comemos simplemente como unidades de producción, considera su bienestar necesariamente secundario al beneficio que ofrecerán sus cuerpos. $Y$ frente a situaciones como las que se viven en la actualidad, no ofrece explicación alguna; explicación que sólo es posible encontrar en los trabajos científicos que investigadores e investigadoras publican de manera independiente y sin recibir la atención de los medios masivos de comunicación hegemónicos.

Este escenario presenta, de todas maneras, alternativas esperanzadoras. En efecto, de acuerdo con la evidencia científica actual, las dietas veg(etari)anas y, particularmente, la estrictamente vegetariana -habitualmente denominada vegana-, son posibles de ser puestas en práctica sin perjudicar la salud humana, son más amigables con el medioambiente y más justas con los demás animales con los cuales compartimos el planeta. El análisis y revisión de la bibliografía producida en las últimas décadas sobre la relación entre veg(etari)anismo y salud muestra que estas formas de alimentación son apropiadas para todas las etapas del ciclo vital, incluidos el embarazo, la lactancia, la infancia, la niñez, la adolescencia y las edades avanzadas e, incluso, para los atletas. Asimismo, han comenzado a reconocerse sus beneficios frente a la prevención 
de patologías de alta incidencia como la diabetes tipo 2, la cardiopatía isquémica, algunos tipos de cáncer, la obesidad, la enfermedad diverticular, las cataratas, la artritis degenerativa, el hipertiroidismo y el síndrome metabólico. Como herramienta terapéutica, la dieta vegetariana estricta resulta efectiva para el control de la diabetes tipo 2, de la obesidad y de otros factores de riesgo (dislipemias) de la enfermedad cardiovascular. En cuanto al medioambiente, es creciente la evidencia que muestra que el cambio masivo hacia dietas basadas en plantas significaría un alivio determinante para los ecosistemas que podrían recuperar biodiversidad, calidad y cantidad de agua potable y de las tierras cultivables, además de la reducción en la emisión de gases de efecto invernadero. Al mismo tiempo, las tierras recuperadas, en lugar de destinarse a la producción de alimento para ganado o a la cría de animales, podrían utilizarse para la siembra de alimentos de calidad para consumo humano.

Sin dudas, es un buen momento - ¿cuándo, si no?- para reflexionar acerca de qué estamos comiendo, cómo producimos los alimentos y para accionar hacia sistemas alternativos y más justos que no pongan en riesgo ni la salud ni la supervivencia de las generaciones futuras de seres humanos y no humanos que, en caso contrario, solo heredarán un planeta devastado.

\section{Bibliografía sugerida para profundizar la temática}

Andreatta, M.M. (2017). ¿Veganos en riesgo? Un análisis de los cuestionamientos habituales a la calidad nutricional de la alimentación vegana. En: Navarro, A. \& González, A.G. (Eds.), Es tiempo de coexistir: perspectivas, debates $y$ otras provocaciones en torno a los animales no humanos (pp. 50-73). Alejandro Korn: Ed. Latinoamericana Especializada en ECA. Disponible en: https://goo.gl/CPfGrJ

González, A.G. (2019). Deshacer la especie: Hacia un antiespecismo en clave feminista queer. Revista TEL, 10 (2), pp. 45-70. Disponible en: https://bit.ly/Deshacerlaespecie Navarro, A. (2016). Representaciones e identidades del discurso especista: el caso de la carne vacuna y sus derivados en la Argentina (2000-2012). (Tesis doctoral). Disponible en SEDICl: http://hdl.handle.net/10915/52068

Navarro, A. \& Andreatta, M.M. (2019). Sistema alimentario carnista y crisis climática: Breve cartografía para comprender el problema. Question, 1 (64). Disponible en: https://doi.org/10.24215/16696581e234 
Pezzetta, S. (2018). Derechos fundamentales para los demás animales. Especismo, igualdad y justicia interespecies. Lecciones y Ensayos, 100, pp. 69-104. Disponible en: http://www.derecho.uba.ar/publicaciones/lye/revistas/100/derechos-fundamentales-para-losdemas-animales.pdf 